\title{
Internet Public Sphere as a Counter-Public Sphere: The Question of Effectiveness
}

\author{
Roshani Dhamala*
}

\begin{abstract}
This article explores the nature of public and counter public spheres by studying some existing scholarships on these topics. It discusses the nature and efficacy of internet, especially the Social Networking Sites, when it comes to serving as public and counter public spheres to facilitate discussion and deliberation within a democratic setting. It then relates the feminist groups of Nepal, who have been relentlessly staging online protest movements against the existing citizenship provision in the constitution of Nepal, with the counter-public groups as described by Frazer. It finally delves into the question of how effective these counter-public groups have been in achieving their proclaimed aim of amending the citizenship provision. Through the literature review of existing literatures on these topics, it elaborates on the possible reasons behind the limited effectiveness of advocacy and protests that take place in the online or digital public sphere. Some of the reasons explored are lack of accessibility to the online platform run through internet, inequality in terms of the accessibility to these platforms because of the digital divide created by caste, gender, and class, disproportionate representation of the voices of social groups, failure of internet based protest movements to ignite enough interest and engagement in the public to bring any major change, and failure of online discussions to follow the high ideals set for deliberative democracy. The paper concludes on a note that in order to make such internet, particularly the Social Networking Sites, based discussions and deliberations more effective and change-causing, there is a need to come up with structural and more formalized procedures to connect such internet based deliberations with the real decision making process.
\end{abstract}

Keywords: Public Sphere, Counter-Public Sphere, online digital protests, Internet and Social Networking Sites

\section{Introduction and Background}

${ }^{*}$ Ms Dhamala is Lecturer in English currently working at Ratna Rajya Laxmi Campus, Tribhuvan University, Nepal. She holds master's degree in English from Pokhara University, Nepal, and also from Virgina Polytechnic Institute and State University (V-Tech), Virginia, USA. 
The new citizenship provision in the Constitution of Nepal, promulgated in September 2015, has run into controversy for being discriminatory on the basis of gender. This provision states that a child born to a Nepali father and a non-Nepal mother is eligible for a citizenship by descent, whereas a child born to a Nepali mother and a non-Nepali father can obtain the citizenship only through naturalization process. Similarly, another clause in this citizenship provision states that a non-Nepali woman married to a Nepali man is eligible for a Nepali citizenship immediately after the matrimony, whereas in the case of a non-Nepali man married to a Nepali woman, the law about the right to citizenship for that man is missing. These provisions in the Constitution of Nepal, once they got promulgated, encountered civic reactions and protests from several public groups, both nationally and internationally.

The feminists groups in particular are vehemently against these citizenship provisions, and they have been demanding its amendment ever since the constitution's formal promulgation. In fact, civil protests against this citizenship protests were organized even before its promulgation when it was only in the drafting phase. It is also important to note that these protests are taking place in both the offline and the online world.

However, not much has changed due to these protests, and the provision was not amended despite these protests. So what went wrong? Why were the feminists' voices not incorporated in the process of constitution drafting and promulgating? Is the reason purely the fact that the lawmakers decided to model the citizenship provision after the ancient Roman model of citizenship, which reinforces male superiority, and deliberately turned their ears deaf to the feminists' protests and demands? Or is this event also telling us something about nature and efficacy of these protests and advocacies conducted by the feminist groups in Nepal, especially in the online/digital platform also calledthe internet public sphere. The answer does not have to be either one or the other of these two: it can very well be the both, or even a combination of a lot of other factors that collectively constitute the socio-political scenario of Nepal, both then and now.

\section{Objective}

This paper explores the nature of public and counter public spheres by studying some existing scholarships on these topics. It then relates the feminist groups of Nepal with the counter-public groups as described by Frazer, and then it finally delves into the question of how effective these counter-public groups have been in achieving their proclaimed aim of amending the constitution.

Plenty of scholarly attention has been directed towards the nature, function and effectiveness of the public sphere and counter-public sphere in political communication and democratic deliberation. So, it is worthwhile to examine these theoretical and 
conceptual models of the public and the counter public sphere. This paper attempts to do that in the first section. It examines the theories of public sphere, with a special focus on the public and counter public sphere in online space of the internet and the World Wide Web. Later, while analyzing the case of Nepal, it forwards an argument that the internet, particularly the social networking sites, provided a space for feminists to conduct their advocacy and protest movements regarding the citizenship provision in the constitution of Nepal. In that sense, the internet serves as a counter public sphere, and feminists who are advocating against the existing citizenship provision act like the counter-public.

However, the effectiveness of what they have been doing can be rightfully called into question, since the constitution provision has not yet been amended. Through literature review of the existing literature on the nature and function of internet, the paper elaborates on the possible reasons behind the limited effectiveness of advocacy and protests that take place in the online or digital public sphere.

\section{Public Sphere and its Function in Political Communication in Democracy}

This section elaborates on the concept or theory of public sphere, and the way it functions within democratic setting. Gaining an understanding of how the founding theorists conceptualized public sphere is instrumental in understanding how it facilitates discussion, deliberation, and protests within a democratic setting. Habermas is one of the first people to conceptualize public sphere in a systematic and scholarly manner. Habermas et al. (1974) provided not just a basic definition of the public sphere and what it means, but also laid a foundation for the theory of public sphere upon which much of the later works on the theory of the public sphere and the counter public sphere was built. This article defines public sphere as "a realm of our social life in which something approaching public opinion can be formed. Access is guaranteed to all citizens...private individuals assemble to form a public body" (Habermas et al., 1974, p. 1). This definition of a public sphere forwarded by Habermas frames public sphere as a free body that functions for the sake of public opinion formation about the matters of the public interest. Fraser (1990) much later also reiterates this idea of the public sphere in her work despite with some reservations and criticisms.

If we look back into the history and understand how Habermas conceptualized the idea of a public sphere, we understand the interrelationship between the terms public sphere and democracy. Habermas et al. (1974) trace the history of public sphere during various socio-political and economic phases of human society. For him, the idea of public sphere came into existence for the first time in eighteenth century - "existed-they grew out of a specific phase of bourgeoisie society" (Habermas et al., p. 3).In the high middle age, there was no distinction as such between public and private. However, 
the sovereignty represented their power "publicly". So, the medieval representative public sphere was related directly to the ruler. However, a process of "polarization" took place during the end of $18^{\text {th }}$ century as a result of which the "private" and the "public" got differentiated. At this point a new kind of public was formed, which constituted of people who held no position inside public bodies and organs of authorities. In fact these people stood in opposition to the public bodies and authorities. Habermas et al., (1974) noted, "Public no longer referred to the "representative" court of a prince endowed with authority, but rather to an institution regulated according to competence, to an apparatus endowed with a monopoly on the legal exertion of authority. Private individuals subsumed in the state at whom public authority was directed now made up the public" (p. 5). This was the bourgeois public sphere, which was the "sphere of private individuals assembled into a public body," (p. 5), and which started communicating through newspapers to speak against the public authority. This practice of communicating via press and assembling together to formulate opinions is something that is facilitated only in a democratic setting.

Habermas' idea of public sphere significantly informs Warner's (2005) understanding of the public. Warner in fact extends Habermas' idea of the public sphere. Like Habermas, for Warner too the public sphere is a private entity that stands in opposition to the state, and possesses self-consciousness about its formation as a critical "reading public" (p. 47). In his book Public and Counterpublics, Warner (2005) defines public and its characteristics. According to him, a public "is self-organized [usually around text]" (p. 67). This particular quality of organizing itself around text, newspapers, and discourses makes the bunch of individuals with their private selfconsciousness a public in the eyes of Warner.

However, Habermas' idea of the public sphere has been criticized for not being democratic enough, in the sense that it fails to take into account the differences that exist between individuals and groups in a society in terms of class, caste, race, gender or power. It also fails to take into account the way these differences impact the nature of deliberations and discussion that take place within the public sphere. Fraser (1990) comes in to fill in this gap, by explaining how a public sphere is constituted and how it functions within a democratic and multicultural or differentiated society.

\section{Nancy Fraser and the Counter-Public}

Fraser (1990) offers one of the most popular and enduring definitions of the term counter public, as well as ideas about how it functions within a democratic society. Fraser (1990) criticizes Habermas of two things: idealizing the public sphere as it existed in the burgeoise society, and falling to take into account multiple and parallel existing competing public spheres within a single society (pp. 60-61). 
Fraser (1990) claims that "the public sphere is always constituted by conflict" and that "there were conflicting publics from the start, not just from the late nineteenth and twentieth centuries as Habermas implies" (p. 61). She also calls the public sphere conceptualized and idealized by Habermas et al. (1974) a "bourgeois masculinist" (p. 62) one.

We can no longer assume that the bourgeoise conception of the public sphere was simply an unrealized utopian ideal; it was also a masculinist ideological notion that functioned to legitimate as emergent form of the class rule...the official public sphere is the institutional vehicle for a major historical transformation in the nature of political domination...the official public sphere, then, was indeed, is - the prime institutional site for the construction of the consent that defines the new, hegemonic mode of domination. (Fraser, 1990, p. 62)

Here, the author is arguing that the idea of a singular public sphere that is representative of all social class and groups in a society is a hegemonic one. So the idea of a dominant public sphere as conceptualized by Habermas is a hegemonic one. Fraser rejects to embrace such hegemonic idea of a public sphere and proposes an alternative.

For Fraser, Habermas' idea of public sphere is hegemonic one because it excludes women's voice and agency. She explains some of the assumptions that underlie Habermas' idea of the unitary public sphere that contribute to making it more exclusive rather than inclusive of everybody in a society. These assumptions are: "it is possible for interlocutors in a public sphere to bracket status differential and to deliberate as if they were social equals", "proliferation of a multiplicity of competing publics is necessarily a step away from, rather than toward, greater democracy," "the appearance of "private interests" and "private issues" is always undesirable" (Fraser, 1990, p.62). She argues that these underlying assumptions keep the Habermas' idea of the dominant public sphere from being inclusive of all social groups and their voices. Fraser (1990) argues that this is not how public sphere functions within an actual society. According to her multiple counter publics exist at once within any society. She calls these "subaltern counterpublics". She explains:

History records that members of subordinated social groups - women, workers, people of color, and gays and lesbians - have repeatedly found it advantageous to constitute alternative public. I propose to call these subaltern counterpublics in order to signal that they are parallel discursive arenas where members of subordinated social groups formulate oppositional interpretations of their identities, interests, and needs. (Fraser, 1990, p. 67)

The feminists groups in Nepal who have been protesting against the existing constitutional provision about citizenship rights for men and women are an example of such counter-publics. These groups, that are diverse in nature and focus, are also an 
example of the way public sphere is constituted and functions within a society that is stratified in its composition and yet believes in facilitating discursive deliberation about the matters related to common interest. In the context of Nepal, such counter public groups like feminists have been using various platforms like social networking sites, blogs, and twitter to conduct their protest movements. In fact, internet happens to be one of the most frequently used spaces, given the fact that is it more easily accessible to the counter-publics in comparison to the traditional print and broadcast media.

\section{Public/Counter-Public and the Internet}

This section elaborates on how internet serves as a platform for public and counter-public groups to voice out their opinions. Due to the unlimited proliferation of the internet in the last decade, it has attracted audiences from all over the world and extended the reach of texts. Public sphere can be anything from a hall where people meet and discussion and have meetings, to a public place where a politician is deliberating his speech or engaging in conversation with his voters or citizens. A public sphere can also be media, both traditional version like print, and digital like television or online, where people participate collectively in opinion sharing, forming and deliberating. Internet in this sense is a public sphere.

Dahlgren (2005) makes a case for the need of such space where people belonging to a myriad of social groups and cultures, and coming from different ethnic and cultural and lingual background find an opportunity for meaningful participation in the discussion and deliberation on the matters that affect them. Dahlgren writes, For about a decade now, many researcher and other observers have been asking whether the Internet will have - or is already having - an impact on the public sphere and, if so, the attributes of this impact...the hope is often expressed that the Internet will somehow have a positive impact on democracy and help to alleviate its ills...yet, given the variations in democratic systems and cultures around the world, and given the pace of change - social, political, and technological - we should not expect to soon arrive at some simple, definitive answer to these questions. (Dahlgren, 2005, p. 1)

Dahl redraws attention to complexity of the matter when it comes to deciding on the impact of internet and digital movements in the democratic deliberation. One thing that problematizes the scenario, he adds, is also the difference that exists due to gender, ethnicity, culture, geography, political orientation, and the like. He argues that the internet offers a space for different groups to work out internal issues and/or cultivate collective identity (p. 60). The World Wide Web and one of its offspring, social networking sites, have created the public sphere on the internet since they offer a space in vast and sometimes unlimited spaces in the forms of blogs, social media pages, and advocacy platforms to everyone irrespective of their social, cultural, economic, and/or 
geographical background. In this sense, the internet public sphere seems to serve the cause of the counter-publics more easily than any other public sphere platform. Goodling (2015) too explains the relationship between the internet and the counter public sphere. She writes, "Where street papers and zines have long served as a vehicle for expression of ideas and individuals who do not fit neatly into a dominant place in mainstream society, online spaces continue to provide an opening and a medium for the establishment of such "counterpublics" (p. 6). She emphasizes that digital media is particularly effective for "disrupting the existing power dynamics in politics and media, making it an ideal situation for activists to do their work" (p. 6). So internet, given its accessibility and vast reach out, can serve as an effective counter-public space in the view of Goodling too.

Internet offers itself as an ideal place for democratic deliberation in today's world. Goodling (2015) argues that the public sphere existing in the social media is a clear and simple extension of the public sphere of the world outside of the internet. She writes, "If social media is examined closely, it becomes clear that the kind of activism conducted digitally encompasses many of the already valued face-face forms of activism" (p. 5). In this sense, internet or digital space for Goodling, is an extension of the real world. In this sense, the digital space might function as effectively as any other non-digital spaces when it comes to protests and advocacy movement in the view of Goodling.

However, in Nepal's case the digital protest movement organized by the feminist counter-public groups on the matter of citizenship provision has not yet succeeded in achieving its initially set aim of bringing about an amendment in the provision. It is important to acknowledge that such online protest movements have been successful enough to raise awareness among the public. Yet, when it comes to the evaluation of these protest movements in terms of the degree to which they have achieved their goals, they still seem to have a long way to go before the ultimate aim is actualized.

\section{Analysis of the Failure of the Digital Media Protest Movement of Nepal}

A qualitative data coding study, guided by the method proposed by Geisler (2004) of the public posts like Facebook, blogs, and the supporting materials form newspaper such as editorials, articles, and features disseminated through the SNSs by the feminist counter public groups in response to citizenship provision reveals that the feminists groups have been arguing that the existing citizenship provision is gendered in numerous ways. The data coding, analysis, and frequency calculation process reveals that such counter-public groups have forwarded several arguments in the online sphere against the existing citizenship provision. Some of most frequently occurring claims made by the feminist counter-public groups in the digital space are: the existing 
citizenship provision promotes unequal treatment by law for men and women, it reinforces patriarchy by putting men first and validating masculine superiority, it goes against the international conventions on human rights and women's rights, and that it brings humiliation and shaming for women, particularly those who have become the victims of rape and trafficking. This result is drawn after compiling a sample of 30 public posts and segmenting 100 set of data for coding.

However, despite all these publications in the internet public sphere, little change is visible in the actual political field: no changes whatsoever have been made to the existing citizenship provision. On the contrary, the makers of this citizenship provision defend and justify the provision on the ground that a provision like this helps national security and integrity by protecting the borders from foreign invasion. Yet, the feminist counter-public groups have not given up on the battle and they are still relentlessly publishing articles, posts, and write ups in the internet public sphere. One of such articles notes, "The issue here is the pitting of nationalism against gender equality - a binary that creates a false dichotomy. The problem lies in the narrow - racist and sexist - definition of Nepali nationalism and 'Nepalipan'. These misogynistic understandings of what it means to be a Nepali must be challenged" (Panta, 2015).

Only the future can show anything about the actual results of these endeavors. However, it becomes important to analyze the significance of this exercise that is unfolding in the realm of internet public sphere. And this brings us to questions like, does digital media, the internet in particular, offer an effective space for activism? Are the voices of the "subaltern counter publics" adequately represented in this sphere, and is it influential enough to bring about actual changes at the policy level? Albrecht (2003) engages in the question of whether or not the internet public sphere offers a space for voicing out the opinion of people who are otherwise normally not heard. And the result he draws is that though it is undoubtable that the internet provides a space where the otherwise underprivileged and underrepresented groups find their spaces, internet and the online public sphere is still not free from limitations.

Proponents of e-democracy assume that the technology of the Internet can be exploited to make the political process more inclusive and deliberative. However, experiences with online communication made so far raise doubts. The digital divide being one obstacle to participation, even more astonishing is the fact that online discourses are constrained in ways similar to those in the offline world. (Albrecht, 2003)

One of the concerns that Albrecht (2003) brings up in his presentation is the problem of digital divide. Albrecht argues that an invisible but prominent division between the rich and poor, the powerful and the marginalized exists in the online environment which constrains the effectiveness of any activism conducted in this space. He emphasizes, "Access to the Internet is not universal, nor is it distributed equally 
among the population of most western countries, but it follows well known factors of inequality, i.e., income, education and race, as well as factors of new inequalities, like gender and age" (p. 4). The digital divide is certainly one of the issues in the case of Nepal too. Not all people have access to the internet, which inhabits both the public's engagement with the civic issues in online space as well as the impact this might have upon public. This fact of inequality in terms of the accessibility to the digital platform can be one of the several reasons why the digital activism of such feminists counterpublic groups is not yet achieving its desired impact in the policy level.

Goodling (2015) too engages in the debate about the merit of new digital form of activism. She ponders on the meaning of change and the effectiveness of physical engagement versus the engagement in the online world to bring about this change. Goodling's primary argument is that "Because of access, convenience, and simplicity of use, the digital realm invites participation from those who might not otherwise be compelled —or able - to participate in person" (p. 1). However, where does this participation lead to, and whether or not it yields any substantive results are the questions that still linger.

In order to strengthen her argument, Goodling also quotes a New Yorker writer Malcolm Gladwell's position on the effectiveness of social media activism. Goodling stresses that social media may not be effective to deliver changes that society requires. She calls these social media activities "the low effort online activities" done by eadvocacy groups that may not always yield tangible results, because often they do not succeed enough in igniting interest and engagement in the public to bring any major change. Dahlgren (2005) agrees with Goodling's argument when he says that although democratic theories posit internet as an ideal space for citizen interaction, "online discussions do not always follow the high ideals set for deliberative democracy" ( $p$. 157).

\section{Conclusion}

Therefore, the factors highlighted by these scholars can very well be the factors that also affect the outcome of digital activism in Nepali digital activism and protest movements. The factors that limit the power of internet public sphere might range from anything like lack of accessibility, to disproportionate representation of the voice of social groups, to the existing socio-political composition of any society at any given time. All these played a role in the case of Nepal, thereby making the digital activism of the Internet public sphere not so powerful.

However, all is not gone. Sparks (2001) offers a solution to this problem. $\mathrm{He}$ writes, "The public sphere, per se is no guarantee for democracy: There can be all kinds of political information and debate in circulation, but there must be structural connections - formalized institutional procedures—-between these communicative 
spaces and the processes of decision making" (p. 75). Therefore, it is up to the future to see if any formalized procedures as suggested by Sparks (2001) to bring together all political information and debate circulating in the online public sphere can effectively be built in the case of Nepal in its contemporary socio-political scenario and if such structure can affect any real time changes in the socio-political scenario of the country.

\section{References}

Albrecht, S. (2003, September 17-20). Whose voice is heard in the virtual public sphere? A study of participation and representation in online deliberation [Conference Presentation]. Research Symposium Information, Communication, Society, University of Oxford.

http://citeseerx.ist.psu.edu/viewdoc/download?doi=10.1.1.85.9101\&rep=rep1\&ty pe $=$ pdf

Dahlgren, P. (2005). The Internet, Public Spheres, and Political Communication: Dispersion and Deliberation. Political Communication 22(2), 147-162. DOI: 10.1080/10584600590933160

Fraser, N. (1990). Rethinking the Public Sphere: A Contribution to the Critique of Actually Existing Democracy. Social Text, 25(26), 56-80.

Geisler, C. (2004). Analyzing streams of language: Twelve steps to the systematic coding of text, talk, and other verbal data. Pearson Longman.

Goodling, L. (2015). MOAR Digital Activism, Please. Kairos: Rhetoric, Technology, Pedagogy19 (3), 1-25.

Habermas, J., Lennox, S., \& Lennox, F. (1974). Public Sphere: an Encyclopedia Article. New German Critique (3), 49-55.

Panta, S. B. (2015, January 2). Citizenship in mother's name: Equality vs. Nationalism debate. Setopati. http://setopati.net/opinion/4931/.

Sparks, C. (2001). The Internet and the global public sphere. In Bennett, W.L. \& Entman, R.M. (Eds.), Mediated politics: Communication in the future of democracy. Cambridge University Press.

Warner, M. (2005). Publics and Counterpublics. Zone Books. 